\title{
Laparoscopic Surgery in Pregnancy and Consequences According to Gestational Age
}

\author{
Nancy Mohamed Ali Rund ${ }^{1 *}$ and Samy Saad Mohamed Ali² \\ ${ }^{1}$ Department Obstetrics and Gynecology, Ain Shams University, Egypt \\ ${ }^{2}$ Department of General Surgery, Ain Shams University, Egypt
}

Submission: February 24, 2019 ; Published: March 13, 2019

*Corresponding author: Nancy Mohamed Ali Rund, Department of Obstetrics and Gynecology, Ain Shams University, Egypt

\begin{abstract}
Introduction: Laparoscopic surgery has been revealed and displayed by various research teams to reduce operative time, postoperative pain, hospital length of stay, recovery time, and wound complications in comparison to laparotomy during pregnancy. However, research efforts and analytical methods should explore the feasibility and safety to perform laparoscopic surgery at different gestational ages. Surgical and anesthetic challenges arise due to anatomical and physiological changes that normally appear as a normal adaptation to pregnancy status.
\end{abstract}

Aim of the Work: The main aim of this research study was to evaluate the clinical and obstetric consequences of interventional laparoscopic procedures conducted during late gestation in comparison to cases conducted in early gestation.

Methodology: The research was conducted in a retrospective manner on 18 cases of laparoscopic surgeries performed during pregnancy from January 2011 till March 2017 comparing cases performed early in pregnancy to those in late pregnancy.

Result: The research data was collected and analyzed from 18 pregnant study subjects that had undergone laparoscopic procedures during the research study period. The mean operative time was significantly lower among women of early pregnancy research group [45.0 $\pm 7.7 \mathrm{~min}$ vs. $57.9 \pm 3.9 \mathrm{~min}$, pvalue $=0.001]$. None of women of early pregnancy group had postoperative complications, in contrast to 3 cases in the late pregnancy group $1(14.3 \%)$ had port-site infection after laparoscopic appendectomy and $2(28.6 \%)$ had threatened preterm labor that was managed by rectal indomethacin for 48 hours; this difference was close to be statistically significant ( $p$ value $=0.059$ ) there were no conversions to laparotomy.

Conclusion: According to the current research findings, laparoscopic interventional procedures in late and early gestation have a high safety profile and with appropriate preparation are considered feasible without any hazardous impact on pregnancy as regards maternal and fetal wellbeing.

\section{Introduction}

The requirement of abdominal surgery during pregnancy is a common concern and issue that integrates the efforts of various subspecialties to perform a multidisciplinary management for those cases scenarios in favor of the maternal and fetal wellbeing. The rates and incidences of abdominal surgery requirement varies widely according to various prior research studies however the cornerstone issue of concern is safety and capability to perform laparoscopic procedures with the great challenge of anatomical and physiological changes that normally exist during pregnancy, that requires laparoscopic surgeon that have the experience and skill to conduct the surgery taking into account the anatomical changes that vary greatly according to the gestational trimester. Research efforts in this aspect are still inadequate and scarce and requires various investigations as regards the type and safety profile of laparoscopic surgery during pregnancy $[1,2]$.

The most frequent etiology in non-gynecological surgical interventions is appendicitis and cholecystitis and the most common gynecological interventional challenges is ovarian torsion and symptomatic adnexal masses requiring both surgical and clinical skills and expertise to have a proper and safe management handling of those clinical scenarios to avoid unnecessary surgical intervention or misdiagnosis $[3,4]$. Laparoscopy in pregnancy is a growing area of interest in research in the last two decades due to the advantages of minimally invasive surgeries although it carries concerns around possible injuries or complications that could affect the maternal and fetal health $[5,6]$. The presence of a viable intrauterine 
gestation with requirement of surgical intervention is a challenge that needs proper counselling and preparation of patients due to the potential risks [7].

\section{Methodology}

This study was carried out in Saudi Arabia, in Jeddah at a private hospital (Bugshan Hospital) for a period starting from January 2011 to March 2017. The patients were provided with an informed consent after receiving a full explanation of the nature and protocol of the study. This study was conducted in a retrospective way the medical records of 18 pregnant cases that performed laparoscopic procedures were reviewed as regards demographic and clinical features and indication of laparoscopic procedure

Performance and clinical outcomes of conducted cases in from January 2011 till March 2017. Usage of tocolytic Therapy preoperatively or postoperatively was conducted on a caseby-case basis, and not in a routine manner. Cases scheduled for laparoscopic surgical intervention have been positioned in the dorsal supine position with slight a left sided tilt to avoid aorto-caval compression by the gravid uterus. Positional changes have been adjusted in harmony and conjugated efforts with the anesthesia team and according to the cases hemodynamic monitoring parameters.

General anesthesia has been implemented in all cases. The laparoscopic and operative trocars placement was adjusted according to uterine size and corresponding gestational age. The following was generally performed as a rule in all cases performed and recruited in the research study in which first gestational trimester cases, Initial placement of the trocar for the laparoscopic procedure was in the umbilicus by positioning a Veress-Palmer needle followed by a $10 \mathrm{~mm}$ trocar. The other regions for trocar placement were decided according to the surgical intervention performed.

Surgical laparoscopic interventions during the second and third gestational trimesters, the preliminary trocar was positioned within the umbilicus or supra umbilical zone, within midline by implementing Hasson open technique, being cephalic a few centimeters to the uterine fundus to avoid entry injuries to the uterus. Laparoscopic procedure insufflation has been conducted using Co2 pressure sustained under $12 \mathrm{mmHg}$ for sufficient venous return, to reduce aorto-caval pressure and avoid subsequent fetal acidosis.

Abdominal structures were intraoperatively manipulated according to the site, symptoms, and features of the pelvic or abdominal pathology using laparoscopic graspers and manipulators to permit adequate and optimal performance of the required interventional surgery, facial layer was closed when above $10 \mathrm{~mm}$ trocars were implemented in the laparoscopic surgical intervention to avoid incisional abdominal hernia. While performing the procedures minimized manipulations of the gravid uterus as much as possible. Routine preprocedural performance of sonographic assessment of fetal wellbeing was performed for all cases and Cardio tocography for gestations above 24 gestational weeks. Post-operative follows up for premature contractions was conducted and tocolytic therapy was administered when required. Sonographic and CTG assessment for fetal wellbeing was repeated after one day from performing the surgical procedure according to the gestational age.

\section{Statistical Analysis}

Inferential analyses were done for quantitative variables using independent t-test in cases of two independent groups, ANOVA test for more than two independent groups with post hoc Tuky's test. In qualitative data, inferential analyses for independent variables were done using Chi square test for differences between proportions and Fisher's Exact test for variables with small expected numbers. Logistic regression was done for factors affecting clinical and completed first trimester pregnancy among the studied cases. The level of significance was taken at $\mathrm{P}$ value $<0.050$ is significant, otherwise is nonsignificant.

\section{Result}

Data presented as mean \pm standard deviation

BMI body mass index (calculated as weight in kilograms divided by squared height in meters)

Analysis using independent student's t-test

Table 1: Initial Characteristics in Included Women.

\begin{tabular}{|c|c|c|c|}
\hline & $\begin{array}{c}\text { Early Preg- } \\
\text { nancy } \\
\text { (N=11) }\end{array}$ & $\begin{array}{c}\text { Late Pregnan- } \\
\text { cy (N=7) }\end{array}$ & P \\
\hline Age (years) & $29.7 \pm 4.0$ & $28.3 \pm 5.6$ & 0.531 \\
\hline Parity & $1.5 \pm 1.0$ & $1.6 \pm 1.3$ & 0.833 \\
\hline BMI $\left(\mathrm{kg} / \mathrm{m}^{2}\right)$ & $26.88 \pm 4.31$ & $26.8 \pm 5.39$ & 0.97 \\
\hline
\end{tabular}

Table 1 reveal and display that 11 study subjects (61.1\%) were in early pregnancy (before 14 weeks of gestation) while 7 cases $(38.9 \%)$ were in late pregnancy. The mean $( \pm \mathrm{SD})$ gestational age of women in the early pregnancy group was $9.39 \pm 1.92$ weeks (range: 7-12.57 weeks), while that in the late pregnancy group was $32.63 \pm 1.05$ weeks (range: $30.43-33.86$ weeks). There were no statistical significant differences between women of both research groups regarding the initial characteristics (age, parity and BMI)(p values=0.531,0.833,0.970, consecutively) (Table 1).

Data presented as number (percentage); median (interquartile range); or mean \pm standard deviation

a) Analysis using chi-squared test

b) Analysis using Mann-Whitney's U-test

c) Analysis using independent student's t-test 
Table 2: Laparoscopy Procedure Characteristics in Included Women.

\begin{tabular}{|c|c|c|c|}
\hline \multicolumn{2}{|c|}{ Early Pregnancy $(n=11)$} & Late Pregnancy $(n=7)$ & $\mathbf{P}$ \\
\hline \multicolumn{4}{|c|}{ Indication for Laparoscopy } \\
\hline Adnexal Torsion & $5(45.5 \%)$ & $0(0 \%)$ & \multirow{5}{*}{$0.238^{1}$} \\
\hline Bowel Obstruction & $2(18.2 \%)$ & $4(57.1 \%)$ & \\
\hline Appendicitis & $2(18.2 \%)$ & $1(14.3 \%)$ & \\
\hline Persistent Mass & $2(18.2 \%)$ & $1(14.3 \%)$ & \\
\hline Calcular Cholecystitis & $0(0 \%)$ & $1(14.3 \%)$ & \\
\hline $\begin{array}{l}\text { Admission-to-In- } \\
\text { tervention Interval } \\
\text { (hours) }\end{array}$ & $6(411)$ & $10(8-11)$ & $0.028^{2}$ \\
\hline \multicolumn{4}{|c|}{ Urgency of Laparoscopy } \\
\hline $\begin{array}{c}\text { Emergent (within } 6 \\
\text { hours) }\end{array}$ & $7(63.3 \%)$ & $1(14.3 \%)$ & \multirow{3}{*}{$0.064^{1}$} \\
\hline $\begin{array}{l}\text { Urgent (within } 24 \\
\text { hours) }\end{array}$ & $2(18.2 \%)$ & $5(71.4 \%)$ & \\
\hline Elective (> 24 hours) & $2(18.2 \%)$ & $1(14.3 \%)$ & \\
\hline \multicolumn{4}{|c|}{ Port of Insufflation } \\
\hline Umbilical & $9(81.8 \%)$ & $0(0 \%)$ & \multirow{2}{*}{$0.004^{1}$} \\
\hline Palmar's Point & $2(18.2 \%)$ & $7(100 \%)$ & \\
\hline Operative Time (min) & $45.0 \pm 7.7$ & $57.9 \pm 3.9$ & $0.001^{3}$ \\
\hline \multicolumn{4}{|c|}{ Intraoperative Complications } \\
\hline None & $10(90.9 \%)$ & $7(100 \%)$ & \multirow{2}{*}{$0.815^{1}$} \\
\hline Bleeding & $1(11.1 \%)$ & $0(0 \%)$ & \\
\hline \multicolumn{4}{|c|}{ Postoperative Complications } \\
\hline None & $11(100 \%)$ & $4(57.1 \%)$ & \multirow{3}{*}{$0.059^{1}$} \\
\hline Port-site Infection & $0(0 \%)$ & $1(14.3 \%)$ & \\
\hline $\begin{array}{c}\text { Threatened Preterm } \\
\text { Labor }\end{array}$ & $0(0 \%)$ & $2(28.6 \%)$ & \\
\hline
\end{tabular}

Table 2 reveals and displays that 11 women of early pregnancy research group, 5(45.5\%) underwent laparoscopy for suspected adnexal torsion, while $2(18.2 \%)$ for bowel obstruction, $2(18.2 \%)$ for appendicitis, and $2(18.2 \%)$ for persistent adnexal mass. On the contrary, of the 7 women of late pregnancy group, $4(57.1 \%)$ were for appendicitis, $1(14.3 \%)$ for persistent adnexal mass, while $1(14.3 \%)$ for persistent pain and vomiting due to Calcular Cholecystitis. These differences were not statistically significant (Table 2).

The median admission-to-intervention interval was significantly lower among women of early pregnancy group $(p=0.028)$, owing to the close-to-be-significant higher rate of emergent (within 6 hours after admission) laparoscopy among women of early pregnancy group $(\mathrm{p}=0.064)$ (Table 2). Among women of early pregnancy group, only 2 (18.2\%) women had the insufflation needle inserted through the Palmar's point (left midclavicular line, subcostal), in contrast to all women [7 (100\%)] of the late pregnancy group; this difference was statistically significant $(\mathrm{p}=0.004)$ (Table 2$)$.
The mean operative time was significantly lower among women of early pregnancy group $[45.0 \pm 7.7 \mathrm{~min}$ vs. $57.9 \pm 3.9 \mathrm{~min}$, $\mathrm{p}=0.001$ ] (Table 2). Only $1(11.1 \%)$ case had significant intraoperative bleeding that required blood transfusion (a case of adnexal torsion who underwent de-torsion and ovarian cystectomy). None of women of early pregnancy group had postoperative complications, in contrast to 3 cases in the late pregnancy group [1(14.3\%) had port-site infection after laparoscopic appendectomy and $2(28.6 \%)$ had threatened preterm labor that was managed by rectal indomethacin for 48 hours; this difference was close to be statistically significant $(\mathrm{p}=0.059)$ (Table 2).

Data presented as mean \pm standard deviation; or number (percentage)

a) Analysis using independent student's t-test

b) Analysis using chi-squared test

Table 3 reveals and displays that the mean gestational age at delivery and mean birth weight were both significantly lower 
in women of the late pregnancy group $[\mathrm{p}=0.006$ and $\mathrm{p}=0.046$, respectively]. Only $1(9.1 \%)$ woman of the early pregnancy group versus $4(57.1 \%)$ women of the late pregnancy group had preterm labor ( $<37$ weeks of gestation); this latter difference was statistically insignificant $(\mathrm{p}=0.093)$ (Table 3).

Table 3: Obstetric Outcome in Included Women.

\begin{tabular}{|c|c|c|c|}
\hline & $\begin{array}{c}\text { Early Pregnan- } \\
\mathbf{c y}(\mathbf{n}=\mathbf{1 1})\end{array}$ & $\begin{array}{c}\text { Late Pregnan- } \\
\mathbf{c y}(\mathbf{n}=7)\end{array}$ & $\mathbf{P}$ \\
\hline $\begin{array}{c}\text { Gestational } \\
\text { Age at Delivery } \\
\text { (weeks) }\end{array}$ & $37.66 \pm 0.77$ & $36.61 \pm 0.53$ & $0.006^{1}$ \\
\hline $\begin{array}{c}\text { Preterm Labor } \\
(<37 \text { weeks) }\end{array}$ & $1(9.1 \%)$ & $4(57.1 \%)$ & $0.093^{2}$ \\
\hline $\begin{array}{c}\text { Birth Weight } \\
\text { (g) }\end{array}$ & $3177.3 \pm 369.7$ & $2814.3 \pm 303.7$ & $0.046^{1}$ \\
\hline
\end{tabular}

\section{Discussion}

Recently laparoscopy have shown great advances in practice and became increasingly popular and more frequently conducted during Pregnancy. Laparoscopy as minimally invasive procedure permits early patient ambulation that avoids serious clinical issues such as deep venous thrombosis. As pregnancy is a hypercoagulable state and thromboembolic events are more frequent in pregnant women consequently early ambulation is considered a desired privilege obtained by laparoscopic approach in surgical management of cases requiring intervention in pregnancy. Even though laparoscopic procedures are feasible in all gestational trimester's injuries are greater issues of concerns as gestation advances since the gravid uterus is at increased risk of injury in late gestational ages raising the risks of prematurity $[8,9]$. Besides the gravid uterus could affect the adequate and proper visualization. The growing uterus may make the traditional umbilical site less desirable. To decrease the risk of laparoscopic entry injuries, it is crucial to consider alternative sites for peritoneal injury, in advanced pregnancy gestation other than umbilical zone $[10,11]$.

In the current research study, a cohort of 18 gravid women undergone laparoscopy during the interval between January 2011 and March 2017; 11 cases (61.1\%) were in early gestation (before 14 weeks of gestation) whereas 7 study subjects (38.9\%) were in late gestation. The mean $( \pm \mathrm{SD})$ gestational age of women in the early pregnancy research group was $9.39 \pm 1.92$ weeks (range: 7-12.57 weeks), whereas that in the late pregnancy research group was $32.63 \pm 1.05$ weeks (range: 30.43-33.86 weeks).

There were no statistical significant differences between women of both research groups regarding the initial characteristics (age, parity and BMI) Of the included 11 women of early pregnancy research group, 5(45.5\%) undergone laparoscopy for suspected adnexal torsion, whereas $2(18.2 \%)$ for intestinal obstruction, 2(18.2\%) for appendicitis, and 2(18.2\%) for persistent adnexal mass. On the contrary, of the 7 women of late pregnancy research group, $4(57.1 \%)$ were for appendicitis, $1(14.3 \%)$ for persistent adnexal mass, whereas $1(14.3 \%)$ for persistent pain and vomiting due to Calcular Cholecystitis. Those differences were not statistically significant.

The median admission-to-intervention interval was statistically significantly lower among women of early pregnancy research group ( $p$ value $=0.028$ ), owing to the closeto-be-significant higher rate of emergent (within 6 hours after admission) laparoscopy among women of early pregnancy group ( $p$ value=0.064). Among women of early pregnancy research group, only $2(18.2 \%)$ women had the insufflation needle inserted through the Palmar's point (left mid clavicular line, subcostal), in contrast to all women [7 (100\%)] of the late pregnancy group; this difference was statistically significant ( $p$ value $=0.004$ ). The mean operative time was significantly lower among women of early pregnancy research group $[45.0 \pm 7.7 \mathrm{~min}$ vs. $57.9 \pm 3.9 \mathrm{~min}, \mathrm{p}$ value $=0.001]$. Only $1(11.1 \%)$ case had considerable intraoperative bleeding that required blood transfusion (a case of adnexal torsion who underwent de-torsion and ovarian cystectomy).

None of cases recruited from early pregnancy research group had postoperative complications, in contrast to 3 cases in the late pregnancy research group [1(14.3\%) had port-site infection after laparoscopic appendectomy and $2(28.6 \%)$ had threatened preterm labor that was managed by rectal indomethacin for 48 hours; this difference was close to be statistically significant ( $p$ value $=0.059$ ).

The mean gestational age at delivery and mean birth weight were both statistically significantly lower in women of the late pregnancy group [ $p$ value $=0.006$ and $p$ value $=0.046$, consecutively]. Only $1(9.1 \%)$ woman of the early pregnancy group versus $4(57.1 \%)$ women of the late pregnancy group had preterm labor ( $<37$ weeks of gestation); this latter difference was statistically insignificant $(\mathrm{p}=0.093)$. A prior similar research study similar to the current research study revealed and displayed that laparoscopic surgeries, could be performed with adequate safety profile despite the indication for surgical intervention in advanced gestations up to 34 weeks $[12,13]$.

As in the non-pregnant cases, laparoscopic surgical approaches have been revealed by various research teams and cases series to reduce operative time, postoperative pain, hospital admission time, period of recovery, and wound complications in comparison to laparotomy during gestation. Various research issues and concerns of grate debate and controversies such as risk of uterine injury and pneumoperitoneum during pregnancy that had make draw backs for performing laparoscopic surgeries in the past $[14,15]$.

Prior research groups have revealed and displayed that $\mathrm{CO} 2$ insufflation triggered maternal hypercapnia, which caused fetal hypercapnia, tachycardia, and hypertension. On the other hand, 
that contradicts with recent research based, evidence that have emerged to show that laparoscopy, even in late gestational ages, could be undertaken safely and is the preferred management modality for many various clinical and surgical scenarios faced in every day practice in pregnant cases $[1,3,16]$.

Laparoscopy could permit better abdominal exploration with less uterine manipulation in comparison to laparotomy that favors laparoscopic approach. the open, closed or optical trocar initial entry techniques are implemented, depending on the fundal height and experience of the surgeon. Left subcostal entry or entry under sonographic guidance have been described to prevent uterine injury. Interestingly $\mathrm{CO} 2$ insufflation pressure levels of $10-15 \mathrm{mmHg}$ are recommended by the Society of American Gastrointestinal and Endoscopic Surgeons for the pregnant cases $[2,4,6]$.

When first trimester ends the organogenesis phase of development is completed, subsequently gestational loss rate falls. Laparoscopic procedures require great skill and experience by the operator to avoid any complications possible due to physiological and anatomical changes in pregnancy which is considered a surgical and anesthetic challenge. in various clinical and surgical scenarios, the surgeon is faced by a restricted by the reduced peritoneal space available to conduct the surgery. Interestingly pregnant cases must be positioned in the left lateral decubitus position to reduce aorto- caval compression, therefore improving venous return and cardiac output. Carbon dioxide insufflation of $10-15 \mathrm{mmHg}$ could be implemented with adequate and acceptable safety levels for laparoscopic surgical procedures in pregnancy $[5,8]$.

Some research studies have revealed and displayed the issue of concern that the intra-abdominal insufflation pressure should be kept under $12 \mathrm{mmHg}$ to prevent deterioration of pulmonary physiological status in gravid cases on the other hand other research teams have claimed that less than $12 \mathrm{mmHg}$ insufflation does not provide enough visualization of the intraabdominal cavity. Additionally $15 \mathrm{mmHg}$ pressure have been implemented during laparoscopic surgeries in pregnant cases without any adverse clinical outcome, whether at maternal or fetal levels [7,11]. Research groups didn't resolve the concern and continuous debate about prophylactic tocolysis therefore all clinicians consider this issue pre or post operatively according to clinical experience and clinical scenarios tailored according to the cases scenario and requirements $[3,7,15]$.

\section{Conclusions and Recommendations for Future Research}

Laparoscopic procedures in pregnancy appears to have a high safety profile levels however future research is recommended to be conducted in multicentric fashion with larger sample sizes and to put in consideration various indications for surgical intervention and different gestational ages. Future research should also consider ethnic and racial differences in anatomical detailed changes that could influence surgical laparoscopic practice approach to aid in future guideline implementation in practice.

\section{References}

1. Chen L, Ding J, Hua K (2014) Comparative analysis of laparoscopy versus laparotomy in the management of ovarian cyst during pregnancy. J Obstet Gynaecol Res 40(3): 763-769.

2. Sachs A, Guglielminotti J, Miller R, Landau R, Smiley R, et al. (2017) Risk Factors and Risk Stratification for Adverse Obstetrical Outcomes After Appendectomy or Cholecystectomy During Pregnancy. JAMA Surg 152(5): 436-441.

3. Nasioudis D, Tsilimigras D, Economopoulos KP (2016) Laparoscopic cholecystodochotomy during pregnancy: a systematic review of 590 patients. Int J Surg 27: 165-175.

4. Pearl JP, Price RR, Tonkin AE, Richardson WS, Stefanidis D, et al. (2017) Guidelines for the use of laparoscopy during pregnancy. Surg Endosc 31(10): 3767-3782.

5. Kizer NT, Powell MA (2011) Surgery in the pregnant patient. Clin Obstet Gynecol 54(4): 633-641.

6. Pillay P, Piercy C, Tolppanen H, Mebazaa A (2016) Physiological changes in pregnancy. Cardiovasc J Afr 27(2): 89-94.

7. Pearl J, Price R, Richardson W, Fanelli R (2011) Guidelines for diagnosis, treatment and use of laparoscopy for surgical problems during pregnancy. Surg Endosc 25(11): 3479-3492.

8. Pearl J, Price R, Tonkin A, Richardson W (2017) SAGES guidelines for use of laparoscopy during pregnancy. Surg Endosc 31(10): 3767-3782.

9. Juhasz-Boss I, Solomayer E, Strik M, Raspe C (2014) Abdominal surgery in pregnancy - an interdisciplinary challenge. Dtsch Arztebl Int 111(2728): 465-472.

10. Chun R, Kirkpatrick A (2012) Intra-abdominal pressure, intraabdominal hypertension, and pregnancy: a review. Ann Intensive Care 2(Suppl 1): 55.

11. Becker C, Plymale M, Wennergren J, Totten C, Stigall K, et al. (2017) Compliance of the abdominal wall during laparoscopic insufflation. Surg Endosc 31(4): 1947-1951.

12. Awoniyi A, Belotte J, Abuanzeh S, Fletcher N, Diamond M, et al. (2014) Advances in the pathogenesis of adhesion development. The role of oxidative stress. Repro Sci 21(7): 823-836.

13. Hatipoglu S, Akbultu S, Hatipoglu F, Abdullayev R (2014) Effect of laparoscopic abdominal surgery on splanchnic circulation: historical developments. World J Gastroenerol 20(48): 18165-18176.

14. Ott D (2012) The pneumoperitoneum. In: Prevention and management of laparoendoscopic surgical complications. In: ( $3^{\text {rd }}$ ed.), Society of Laparoendoscopic Surgeons, Miami, USA.

15. Binda M (2015) Humidification during laparoscopic surgery: overview of the clinical benefits of using humidified gas during laparoscopic surgery. Arch Gynecol Obstet 292(5): 955-971. 
CC This work is licensed under Creative DOI: 10.19080/JGWH.2019.14.555889
Your next submission with Juniper Publishers will reach you the below assets

- Quality Editorial service

- Swift Peer Review

- Reprints availability

- E-prints Service

- Manuscript Podcast for convenient understanding

- Global attainment for your research

- Manuscript accessibility in different formats

( Pdf, E-pub, Full Text, Audio)

- Unceasing customer service

Track the below URL for one-step submission https://juniperpublishers.com/online-submission.php 